\title{
Transformations in Health Law Practice: The INTERSECTIONS OF CHANGES IN HEALTH CARE AND LEGAL WORKPLACES
}

\author{
Louise G. Trubek, Barbara Zabawa, Paula Galowitz*
}

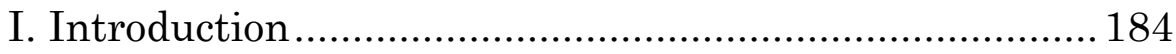

II. Background and Context for Health Law Practice ..... 185

A. Health Care System Changes................................ 186

B. Legal Services in Flux........................................... 188

III. Health Law Workplace Sites ..................................... 191

A. Outside and Inside: In-House Counsel and Corporate

Law Firms.......................................................... 191

1. Increasing Reliance on In-House Counsel................ 194

2. Defining the Roles of the Outside Health Lawyer... 197

B. Expanding Medical-Legal Partnerships..................202

IV. Learning From The Workplaces: Reconstructing

Lawyers' Professionalism Identity.....................................209

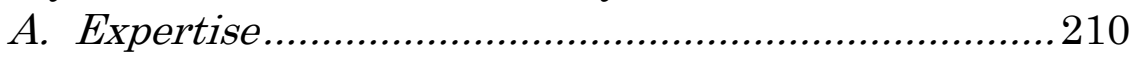

1. Legal Expertise for Improved Patient-Centered

Care..........................................................................2 211

2. Legal Expertise to Resolve Complaints...................212

3. Legal Expertise to Strengthen Business Decisions ... 213

B. Roles: The Lawyer as Colleague with Physicians and Other Professionals ................................................214

C. Communities of Practice .......................................218

V. Training for Practice ..................................................220

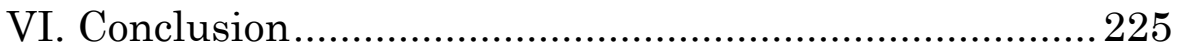

* Louise Trubek, Clinical Professor of Law Emerita, University of Wisconsin Law School; Barbara Zabawa, Owner of the Center for Health Law Equity, LLC; Paula Galowitz, Clinical Professor of Law Emerita, New York University School of Law. The authors would like to thank Laura Green for her invaluable research assistance. Also, the authors would like to thank the Madison Roundtable participants for their insightful comments, including Sarah Davis (University of Wisconsin Law School), Erika Lopez (Legal Action of Wisconsin), Paul Van Den Heuvel (Mercy Health System), Christine Senty (Unity Health), Christine Witherill (WPS Health Insurance), Dennis Purtell (Whyte Hirschboeck Dudek), and Kim Shaul (National Guardian Life Insurance). 


\section{INTRODUCTION}

The practice of health law is undergoing radical restructuring in the wake of major changes in the health care system and the reorganization of the legal profession. The health care system is being transformed as the Affordable Care Act (ACA) promotes shifts in how health care should be delivered and financed. These shifts come at a time when the legal profession is also undergoing significant transformations.

The intersection between health care changes and professional legal services can be examined by focusing on health law workplaces. This paper discusses three workplace sites where lawyers are developing or revising practices that respond to the evolving health care system. These workplace sites are in-house counsel, corporate law firms, and medical-legal partnerships. This paper describes how in-house counsel are growing and incorporating compliance and business advising into their practice. Corporate law firms are developing niches where their independent advising is valued. Medical-legal partnerships are expanding and using their close interactions with the health system to change their relationships with health care professionals and to provide increased legal expertise to patients.

This analysis reveals how the professional identities of the lawyers are evolving as their practices change. This paper discusses three aspects: rethinking how expertise assists clients; the role of lawyer as collaborator with other professionals; and how communities of colleagues in similar practice facilitate the development of revised professional identities. Finally, this paper focuses on how training, especially legal education can reflect and adapt to these workplace practices. In this period of re-thinking legal education, perhaps the health practice stories can cast some light and assist in the re-visioning of legal education. 


\section{Background ANd ConteXt For Health LaW Practice}

Health law is a significant field of specialization. For example, there are specialized law journals in health law; certificate programs in health law within the juris doctor (JD) curriculum at law schools; joint degree programs with schools of public health; and organized bar committees for health law practitioners. ${ }^{1}$ Recently, the media have identified health law as one of the few growing areas of the legal profession. ${ }^{2}$ One reason for the predicted growth is the enactment and implementation of the ACA. Since its enactment in 2010, the ACA has been in the news, most recently because of its rocky rollout. ${ }^{3}$ However, the

1 See e.g., Health Law Journals, FindLAw, http://stu.findlaw.com /journals/health.html, archived at http://perma.cc/B2FY-R253 (last visited Dec. 27, 2014); Formal JD/MPH Degree Programs, LAW, SCIENCE $\&$ Public HEAlth Program Site, http://biotech.law.lsu.edu /Courses/PH_Courses/jd-mph01.htm, archived at http://perma.cc/Z2T2TGAX (last visited Dec. 27, 2014); Health Law Programs, AM. HEALTH LAWYERS ASS'N, http://www.healthlawyers.org/hlresources/Academics /LawProfessors/Pages/HealthLawPrograms.aspx, archived at http://perma.cc/74E7-2HP2 (last visited Dec. 27, 2014); Health Law Section, AMERICAN BAR ASS'N, http://www.americanbar.org/groups /health_law.html (last visited Dec. 27, 2014); see also AM. HEALth LAWYERS ASS'N, http://www.healthlawyers.org/Pages/Default.aspx, archived at http://perma.cc/8F7M-N7EB (last visited Dec. 27, 2014).

2 Delece Smith-Barrow, A Changing Health Industry Offers Opportunities for Lawyers, U.S. NEWS \& WORLD REPORT (Nov. 25, 2013), http://www.usnews.com/education/best-graduate-schools/top-lawschools/articles/2013/11/25/a-changing-health-industry-offers-

opportunities-for-lawyers, archived at http://perma.cc/9AKG-SWWD; See also Mike Stetz, Super Hot: Health Law, 23 The NAT'L JuRIST 8 (2014).

3 See e.g., Timothy Stoltzfus Jost \& Simon Lazarus, Obama's ACA Delays - Breaking the Law or Making it Work? 370 NEW ENG. J. MED 1970 (2014). The Affordable Care Act is creating short-term crises that are well publicized. These delays and modifications create confusion for patients, providers, and health care organizations. Some of these are the employer mandate delay, 2014 Open Enrollment Period delays, changes in the Department of Health and Human Services (DHHS) right to renew existing plans, modifying requirements "encouraging" insurers to allow people flexibility in enrollment, and delay in nondiscrimination provision. These crises are likely to be of short duration, though of significant concern for lawyers and their clients. 
importance of the legislation is not the short-run delays and confusion; it is the proposed long-term goals for health care.

\section{A. Health Care System Changes}

The ACA promotes health care improvements through encouraging seven shifts in how health care is delivered and financed. These shifts include movements toward: 1) patient-centered, collaborative care; 2) value-based and evidence-based care; 3) integrated regional clinics and hospitals; 4) integration of prevention and community medicine; 5) a computerized and benchmarked business model; 6) transparency and information sharing in health care; and 7) universal coverage using public-private systems.

The first is the shift from doctor as expert to patientcentered and multiprofessional collaboration. The shift towards patient-centered care places discussion and coordination with the patient and family as a key part of treatment, minimizing unnecessary treatment and adverse reactions. ${ }^{4}$ Multiprofessional collaboration involves members of different health care disciplines and perspectives, working together and supplementing each other's expertise to determine the best treatment for a patient.

The second is the change from volume-based payments to value- and evidence-based treatment. There is a shift from payments based on the amount of treatment the patient receives to payments based on the benefit the patient receives from treatment, and decisions that are based on evidence of effectiveness. ${ }^{5}$ A value-based model is touted as improving patient outcomes, creating

\footnotetext{
4 James Rickert, Patient-Centered Care: What It Means And How To Get There, HEAlth AfFaIRs BLOG (Jan. 24, 2012), http://healthaffairs.org/blog/2012/01/24/patient-centered-care-what-itmeans-and-how-to-get-there/, archived at http://perma.cc/T8NP-UBLV.

5 Gloria N. Eldridge \& Holly Korda, Value Based Purchasing: The Evidence, AM. J. MANAGED CARE (Aug. 9, 2011), available at http://www.ajmc.com/publications/issue/2011/2011-8-vol17n8/ajmc_11aug_eldridge_e310to13/1, archived at http://perma.cc/6UTRMMLD.
} 
accountability, being cost efficient, as well as reducing inequities. ${ }^{6}$

The third change in health care delivery and evaluation is the dramatic shift from doctors and hospitals as separate legal institutions to integrated regional clinics and hospitals. Integrated regional clinics serve as the "one stop shop" for health care, where clinicians from various disciplines will be in the same place. These clinicians work in multidisciplinary teams to ensure the best patient outcome.

Fourth, instead of public health as a separate field, there is integration of prevention and community medicine with acute care medicine, such as that traditionally provided by hospitals and physician clinics. Community medicine focuses on the health care needs of a specific group or population. ${ }^{7}$ Preventive treatment is determined and provided based on that analysis. ${ }^{8}$

The fifth shift in health care is from the business of health care as small practices and unconnected care to a computerized and benchmarked business model. A benchmark business model creates a set of "best practices" and standards. ${ }^{9}$ This creates a uniform set of standards and goals to be met by hospitals and practitioners. ${ }^{10}$

The sixth shift is from health care as an opaque separate world to one of transparency and information sharing. Moving towards a system of transparency, consumers will be provided with cost and quality information in order to choose health care providers. Consumers taking an active role in health care decisions will lead to increased

\footnotetext{
$6 I d$.

7 Mary A. Pittman, As Country Moves Closer to Near-Universal Coverage, Community Health and Prevention Must Become Focus of Healthcare, Public Health Institute Blog (Oct. 1, 2013), https://www.phi.org/news-events/545/as-country-moves-closer-to-nearuniversal-coverage-community-health-and-prevention-must-becomefocus-of-healthcare, archived at https://perma.cc/3EYX-2UGU.

8 Id.

9 Pietro Giorgio Lovaglio, Benchmarking Strategies for Measuring the Quality of Healthcare: Problems and Prospects, 2012 THE SCIENTIFIC WORLD J. 1 (2012).

$10 I d$.
} 
competition and premium savings in the health care system. One way in which transparency is increased is the requirement in the ACA that health plans submit information on "cost-sharing and payments with respect to any out-of-network coverage,"11 with periodic disclosure of financial information. ${ }^{12}$

The last shift in health care delivery and evaluation is the one from uninsured and safety net care to universal coverage using public-private systems. Safety net care is providing the uninsured with health care through a variety of different providers, such as free clinics and public hospitals. This safety net system of treatment for the uninsured has become a patchwork system with very little coordination. Universal health coverage is accomplished by expanding public and private insurance coverage and care by mandates, subsidies, payment reform encouraging care coordination, and insurance exchanges.

\section{B. Legal Services in Flux}

At the same time that the health care system is struggling to become integrated, transparent, and collaborative, the organization of the delivery of legal services is also undergoing changes. The legal profession is often described as two hemispheres: personal services and business practice. There are changes in the practice of each hemisphere. In the business practice sphere there is the growth of in-house counsel offices. In the personal services sphere, there is increased concern about the lack of access to legal services.

According to one legal scholar, large companies continue to increase the number of attorneys employed in-house. ${ }^{13}$ Some legal scholars believe that lawyers on the inside of an

1142 U.S.C. $\S 18031(\mathrm{e})(3)(\mathrm{A})(\mathrm{vii})(2015)$.

12 Id. § 18031(e)(3)(A)(i)-(v) (2015); Memorandum from Laura Green, Student Research Assistant, Seton Hall University School of Law, for Louise Trubek, Clinical Professor of Law Emerita, University of Wisconsin Law School (Jan. 6, 2014) (on file with author and recipient).

13 Interview with Kathleen M. Boozang, Associate Dean and Professor of Law, Seton Hall Univ. Sch. of Law (Dec. 11, 2013). 
entity are better equipped to give advice because they understand the company's business and therefore know which guidance and news is relevant to the company, and which is not. ${ }^{14}$

In 1980, approximately ten percent of licensed attorneys were practicing in-house. ${ }^{15}$ By 2000, the amount of licensed, in-house attorneys increased by forty percent. 16 In-house attorneys are beginning to do work that was traditionally done by outside counsel. ${ }^{17}$ According to one survey, about sixty-eight percent of transactions are currently performed in-house. ${ }^{18}$ Moreover, in-house attorneys command greater respect in the legal profession than they once did. ${ }^{19}$

A key driver behind the surge in number of in-house counsel is that they provide a lower cost alternative to law firm services. ${ }^{20}$ By moving legal work in-house, a company could avoid large legal fees paid to law firms and avoid duplicative work and miscellaneous expenses. ${ }^{21}$ However, cost savings is not the only driver behind the increased use of in-house counsel. Inside lawyers are in a better position than outside lawyers to "understand the company's business and to engage in the kind of risk assessment and preventative counseling that managers need to survive in

14 Id.; see also David B. Wilkins, Is the In-House Counsel Movement Going Global? A Preliminary Assessment of the Role of Internal Counsel in Emerging Economies, 2012 WIS. L. REV. 251, 259 (2012).

15 Eli Wald, In-House Myths, 2012 WIS. L. REV. 407, 419 (2012) (observing that in-house legal departments do not offer any better shot at gender equality than large law firms) [hereinafter Wald, In-House Myths].

16 Id.

17 Id.

18 Jonathan Lipson et al., Foreword: Who's In the House? The Changing Nature and Role of In-House and General Counsel, 2012 Wis. L. REV. 237, 243 (2012).

19 Id. (noting that "[t]oday the [in-house counsel position] attracts well-known partners from elite corporate firms, typically carries a senior title within the corporate hierarchy, and is associated with significant prestige within the legal profession.").

20 Id. at 242.

21 Boozang, supra note 13; see also Wilkins, supra note 14, at 259. 
an increasingly complex and turbulent legal environment." 22 Indeed, a qualitative study of general counsel from the 1990s showed that fifty percent of those sampled saw themselves as "consigliere for senior executives giving advice on matters at the intersection of business and law."23 Surveyed in-house lawyers also saw themselves as entrepreneurs who viewed their legal role as not merely a necessary complement to corporate functions, but as one of a number of ways in which lawyers could further the business interest of the company. ${ }^{24}$ Moreover, in addition to providing effective advice, inside lawyers believe they are able to provide "independent professional judgment" that is essential to a company. ${ }^{25}$

The traditional corporate law firms are also changing to meet the changing needs of its existing clients and to obtain new clients. Instead of training lawyers to be general counsel to corporations, traditional law firms are emphasizing specialization in legal knowledge and fostering niche practice areas in various industries, including health care. This gives rise to different types of large law firms that follow different patterns of growth. ${ }^{26}$ In the personal service sphere, there is the continued shortage of legal assistance for people without significant resources. ${ }^{27}$ Civil legal assistance for poor and disadvantaged people is provided by legal services offices staffed by federally funded lawyers, law offices staffed by lawyers funded from other sources, and pro bono services provided by programs organized to assist the underserved. In terms of the number of lawyers involved, pro bono is now the largest

22 Wilkins, supra note 14, at 259.

23 Id. at 261-62.

24 Id. at 262.

25 Id. at 261.

26 Eli Wald, Smart Growth: The Large Law Firm in the TwentyFirst Century, 80 FordHAM L. REv. 2867 (2012) [hereinafter Wald, Smart Growth].

27 See Gillian Hadfield, The Cost of Law: Promoting Access to Justice Through the Corporate Practice of Law, USC LAW LEGAL STUDIES PAPER NO. 12-26 (2012), available at http://papers.ssrn.com/ sol3/papers.cfm?abstract_id=2183978, archived at http://perma.cc/U7EB-3ZBP. 
component of civil legal assistance. ${ }^{28}$ Partly as a result of the shortage of government funding, there has been the emergence of public/private provision of legal services to the poor and disadvantaged; pro bono attorneys, law students, and non-lawyers can meet these needs. ${ }^{29}$ This is a period of searching for new ways to provide access to justice.

\section{Health LaW WorkPlace Sites}

Health care lawyers are caught up in the dual transformations of health care and legal organization as the nature and setting for their practice changes. This paper concentrates on two types of practice: the corporate law sector that serves business and the "access to justice" sector that assists individuals. These practices serve very different clients. These sites might be seen as the far ends of the continuum of legal practice. However, by examining these specific practices, the challenges to health care lawyers caught in the transformation of the nature and setting for their practices is illuminated. The examination of these changes in such different settings highlights how health care lawyers adapt their practices. In the corporate sector, the integration of hospitals and clinics, the incentives for value-based care, and the mandated public reporting on costs and outcomes is changing the relationship between the corporate law firm and its clients. In the access to justice sector, increased emphasis on patient centeredness, integration of acute and public health, and expansion of subsidized coverage makes health law a focus for improving the lives of poor and disadvantaged people.

\section{A. Outside and Inside: In-House Counsel and Corporate Law Firms}

The trend of increasing reliance on in-house counsel can be seen in health care. Because health care is a highly

28 Rebecca Sandefer, Lawyers' Pro Bono Service and AmericanStyle Civil Legal Assistance, 41 LAW \& Soc'Y REV. 79 (2007).

29 Id. 
regulated industry, and is increasingly so, the need for lawyers pervades.30 Although this demand for lawyers includes those who practice in-house as well as in outside law firms, ${ }^{31}$ the roles of each are shifting to meet the evolving needs of health care organizations. One pronounced shift is the growing role of general counsel inside health care organizations. According to some legal scholars, as discussed earlier in this paper, lawyers on the inside of an entity are better equipped to give advice because they understand the company's business and therefore know which guidance and news is relevant to the company, and which is not. ${ }^{32}$

However, the role of the traditional, or "outside" corporate lawyer, is also being revised, particularly in health care. The changes can be summed up as follows: whereas the outside health lawyer once occupied the role of gatekeeper for a health organization's various legal needs, the growth of in-house counsel in health care organizations has changed the role of the outside health lawyer. This is true with regard to a corporate law firm's traditional clients, which often include health care systems (both acute and long-term care), practitioners, and health insurance plans. These clients once relied on outside law firms to handle most of the organization's needs. The firms offered overall knowledge of the health care regulatory landscape and were equipped to handle tax, anti-trust, corporate transactions, employment, and real estate matters. In essence, the outside health lawyer orchestrated general counsel services for the organization.

The health sector is increasingly moving the general counsel role in-house for two primary reasons: (1) so that a legal advisor is intimately involved in business operations and strategic planning and (2) due to the exponential growth in regulations leading to rising legal costs. Hiring

30 Jennifer Smith, Want a Law Job? Learn the Health-Care Act, WALL ST. J. (June 16, 2013, 11:40 PM), available at http://online.wsj.com/news/articles/SB1000142412788732404950457854 5460856078702, archived at http://perma.cc/T3BQ-5LA4.

31 Id.; Boozang, supra note 13.

32 Boozang, supra note 13; see also Wilkins, supra note 14. 
in-house counsel helps health care organizations address regulatory change as part of business strategy and, simultaneously, controls the costs of legal services. Despite moving more legal services in-house, health care organizations still rely on outside counsel, albeit for very specific projects. Outside health lawyers with highly specialized skills, that in-house offices may need from time to time but cannot staff on a regular basis, are an important component to the health law landscape. Furthermore, smaller health care organizations that are unable to afford to hire in-house counsel still need outside health lawyers to guide it through the regulatory land mines that do not discriminate based on an organization's size.

Regardless of the organization's size, health care clients seek to improve their bottom line as well as share a desire to serve patients or enrollees and ultimately improve health, even if such improvement is not the most efficient or cost effective way for society as a whole. The health lawyer may be seen as sympathetic to these dueling goals and, thus, a trusted advisor for health care clients, whether working in-house or in a law firm.

The pressing question for health lawyers, whether future, new, or existing, is how they can utilize their skills in-house and in a law firm, especially as health care law continues to evolve. Typical health lawyer skills consist of knowledge of the health care regulatory landscape, as well as an understanding of, or at least an appreciation for, the business side of health care. Mastering a wide variety of laws such as Stark (limitations on physician self-referral of Medicare and Medicaid patients), Anti-Kickback, Medicare and Medicaid reimbursement and Conditions of Participation, the Health Insurance Portability and Accountability Act (HIPAA), state licensing laws, provider credentialing, Employee Retirement Income Security Act (ERISA), state insurance regulation, and payor contracting principles are staples in health law curricula and practice. ${ }^{33}$

${ }^{33}$ See e.g., Fundamentals of Health Law CLE Programs, AM. HEALTH LAWYERS ASS'N (2012), available at https://www.healthlawyers.org/store $/$ Pages $/$ Product-Details.aspx productid $=\{5$ A554EDF-0235-E411-93B6- 
Since 2010, many health lawyers are also now expected to know the various provisions of the ACA. ${ }^{34}$ The next two sections examine how health lawyers are applying these skills in-house and in law firms.

\section{Increasing Reliance on In-House Counsel}

Health care clients are especially relying on in-house counsel to help navigate the ACA's provisions and strategize about the organization's future initiatives. ${ }^{35}$ Enforcement delays, along with burgeoning lawsuits challenging various aspects of the law, make it difficult for stakeholders to plan for and implement the ACA. ${ }^{36}$ The level of uncertainty presented by the ACA causes companies to bring in-house lawyers into more strategic advising sessions and then to turn to the general counsel for guidance. ${ }^{37}$ Furthermore, inhouse lawyers assist health care organizations in managing increasing consumer expectations.38 Unlike the tepid consumer reaction to the roll-out of the HIPAA privacy and security regulations, the ACA is pushing consumers to be much more savvy and active in their health care and coverage - the commodity sold by health care clients. General counsel have commented that health care consumers are much more sophisticated than in the past and therefore playing a larger role in evaluating health care services and products. ${ }^{39}$ ACA initiatives, such as Accountable Care Organizations (ACOs) and health

00505692001D\}. .

34 Id.

35 Roundtable Discussion, Univ. of Wis. Law School, Madison (October 24, 2013) [hereinafter Madison Roundtable].

36 See supra note 3.

37 The increasing importance of the in-house counsel appears to be moving from the West of the United States to the East. This is because the integrated health care model started in the West and Upper Midwest and is just beginning to take hold in the East. As the changes in health care take hold, we can expect to see the growth and shifts in the in-house counsel emerge throughout the country.

38 Madison Roundtable, supra note 35.

39 Id. 
information exchanges, require greater consumer engagement. 40

In addition, the growing trend in transparency to provide health care consumers with greater access to standardized health care quality and cost data, such as that being provided by the Wisconsin Health Information Organization, ${ }^{41}$ will likely lead to provider concerns about liability and marketplace reputation. ${ }^{42}$ Health care organizations will seek legal advice and assistance to traverse potential disputes that arise from performance standardization and enhanced consumer knowledge about the inputs of health care. ${ }^{43}$ In-house professionals now seek to utilize malpractice claims to locate potential problems within the organization. ${ }^{4}$ The disputes that derive from disagreements about the use of performance standards and from claims of malpractice are increasingly important. The disputes provide data and information that can be utilized by the in-house counsel to refine the quality and safety systems now required by federal regulation. ${ }^{45}$

The ACA framework has enhanced the need for the skills of the lawyer and the role of the in-house counsel, not only on the business end but also in overseeing the quality dimensions. The move towards value, evidence-based care,

40 Id.; see also Barbara J. Zabawa et al., Adopting Accountable Care Through the Medicare Framework, 42 SETON HALL L. REV. 1471 (2012).

41 Home, Wis. HEALTH INFO. ORG., http://www.wisconsinhealthinfo. org/ (last visited Dec. 27, 2014) (The Wisconsin Health Information Organization is a voluntary initiative supported by insurance companies, health care providers, major employers, and public agencies that has created "one of the most comprehensive sources of health claims information available anywhere in the United States.").

${ }^{42}$ Guy Boulton, Group Seeks Medicare Data to Increase Health Care Efficiency, MilwaukeE. J. Sentinel (Jan. 11, 2014), http://www.jsonline.com/business/group-seeks-medicare-data-toincrease-health-care-efficiency-b99181177z1-239783441.html, archived at http://perma.cc/QMH7-9QJE.

43 Michael D. Roth \& Leonard M. Fromer, Identifying and Resolving Disputes in New Accountable Care Settings, Am. Health LaWYeRS Ass'N ConneCTiOns, Dec. 2013, at 14-23.

44 Joanna C. Schwartz, A Dose of Reality for Medical Malpractice Reform, 88 N.Y.U. L. REV. 1224 (2013).

45 Id. 
and integration of care makes essential the coordination among audit, safety, compliance and legal counsel sectors within the health care organization. The in-house counsel often serves as the coordinator among staff that works in various areas of corporate compliance, quality and audit. Moreover, corporations are seeking lawyers to fill compliance and audit roles once filled by non-lawyers. ${ }^{46}$ For example, the move toward payment systems tied to high quality and value creates significant potential for legal disputes. ${ }^{47}$ Disputes may arise over shared savings, failure to meet quality benchmarks, or overutilization of high-cost procedures or out-of-network care. ${ }^{48}$ Lawyers who have knowledge about these initiatives as well as the legal system generally can help health care organizations navigate through these potentially expensive and disruptive disputes. ${ }^{49}$

In addition to using lawyers to perform tasks previously performed by non-lawyers, health care organizations use inhouse counsel for much of the work done previously by outside law firms, such as routine corporate legal paperwork and strategic decision-making in matters such as mergers, acquisitions and larger-scale litigation. ${ }^{50}$ This is partly due to companies expecting in-house counsel to control spending on outside legal work. ${ }^{51}$ As a result, inhouse counsels decide what work should be performed inhouse and which firms to use for outsourced work. ${ }^{52}$ Moreover, because HIPAA requires "covered entities" such as providers and payers to have a dedicated HIPAA privacy officer, ${ }^{53}$ HIPAA compliance, at least in part, must be inhouse. Finally, the increasing interest in in-house work relates in part to the gender aspect. Balancing work and family is often seen as easier if working as an in-house

\footnotetext{
46 Madison Roundtable, supra note 35.

47 Roth \& Fromer, supra note 43.

48 Id.

49 Id.

50 Wald, In-House Myths, supra note 15, at 413.

51 Lipson, supra note 18, at 242 (noting that controlling spending on outside legal work is a top priority for in-house counsel).

52 Id. at 243.

5345 CFR § 164.530(a)(1) (2014).
} 
attorney. ${ }^{54}$ Lawyers may also see that combining social good and economic well-being is easier in the in-house role.

\section{Defining the Roles of the Outside Health Lawyer}

People do not often associate corporate lawyers as being crucial to improving social goods like health care, but opportunities for such improvement arise in the corporate transactional and regulatory world. It is the corporate lawyer's role as an advisor, specialist and creative thinker that clients value. The literature suggests that outside health lawyers can provide value to health care clients in two primary ways: through legal opinions independent of solely business interests and through very specialized practice areas. ${ }^{55}$

The function of the outside lawyer has been shaped in part through increased competition and structural changes in the legal market for corporate legal services. ${ }^{56}$ Increasing numbers of law firms created competition in the market for legal services, causing corporate clients to turn to different law firms to handle various legal needs. ${ }^{57}$ In addition, rising numbers of in-house legal departments allowed corporate clients to "both handle some of their basic legal and corporate paperwork internally and more effectively manage their overall legal needs, cutting costs and eliminating a significant income source for large law firms." 58 As in-house counsel assumed greater responsibility, the opportunities for outside lawyers to provide regular, general and continuous legal services to

54 Better on Balance? The Corporate Counsel Work-Life Report, Program ON WORKLIFE LAW, AM. UNIV., at 17 (Dec. 2003), http://worklifelaw.org/Publications/BetterOnBalance.pdf, archived at http://perma.cc/42GE-TEXN (last visited Dec. 28, 2014).

55 See e.g., Robert Gordon, The Ideal and the Actual in the Law: Fantasies and Practices of New York City Lawyers, 1870-1910, in THE NEW High PRIESTS: LAWYERS IN POST-CIVIL WAR AMERICA 51 (Gerard W. Gawalt ed., 2010); Wald, In-House Myths, supra note 15; Lipson et al., supra note 18.

56 Wald, In-House Myths, supra note 15, at 414.

57 Id.

$58 I d$. 
corporate entities dwindled. ${ }^{59}$ As a result, outside lawyers were increasingly limited to "ad hoc, high-profile, unique and specialized representations," under the supervision of in-house counsel. ${ }^{60}$ It is the ability of the outside lawyer to represent corporate clients, such as health care organizations, in unique, high-profile or specialized matters that creates value for corporate clients.

The role of the outside corporate lawyer as an independent voice in a regulatory and political quagmire has early roots in American legal history. As noted by Robert W. Gordon, who wrote about corporate law practice in the late nineteenth century and early twentieth century, the demand for corporate legal services is at least partially a function of the American political ideologies of liberal individuals and that corporate power must serve the public ends of the common wealth. 61 Corporate lawyers in the mid-1880s served as legal brokers and intermediaries between large American corporations trying to attract new capital in the process of consolidation or of reorganization after bankruptcy, and the investment banking communities of Wall Street and Europe that supplied most of the capital. 62 "[L]awyers invented for themselves liaison roles in building or rebuilding financial structures of American corporations that ensured the prosperity of the largest New York City law firms and came to seem indispensable to their clients."63

Thus, outside corporate lawyers may distinguish themselves from in-house counsel by not allowing themselves to "be absorbed by their business clients."64 Instead, corporate lawyers exist in independent firms, which allow them to more easily see adverse long-run effects of decisions in the wider social, political, regulatory and business community. ${ }^{65}$ The outside lawyer can serve as

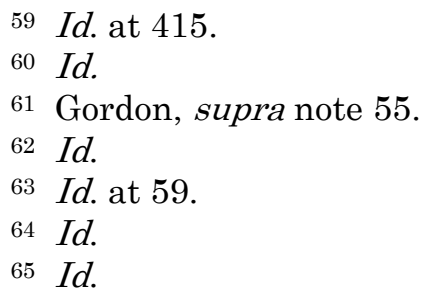


the liaison between corporate management and the greater community. In a more cynical view of the use of outside lawyers,

[clients] want lawyers to fend off or neutralize [the community, pro bono benefit] or to invent or lobby for new legal forms that circumvent the restrictions, or, perhaps most important, to find ways of writing the restrictions so as to reassure people that corporate conduct within them is safe and legitimate. 66

A legal opinion from an independent, outside lawyer is very valuable in securing reassurance that a particular strategy is permissible.

As one general counsel stated recently, in-house counsel go to outside law firms to get a "yes" regarding a plan or strategy desired by management. ${ }^{67}$ Because health care organization management increasingly involves in-house lawyers with strategic planning, in-house counsel seek protection from those strategic decisions by seeking advice and guidance from outside counsel.68 Thus, outside corporate law firms are essential in navigating ethical and conflict of interest issues, as well as offering an independent point of view that provides security to various business decisions. ${ }^{69}$

In addition to an independent legal opinion, recent articles and publications indicate that another use of outside counsel, particularly for health care organizations, involves specialty practice areas that in-house lawyers do not have time to master. "Even companies with robust inhouse law departments are increasingly calling on outside lawyers who specialize in the most arcane corners of healthcare law."70 Some of those arcane corners of health care law

66 Id.

67 Madison Roundtable, supra note 35.

68 DAVID J. GALBENSKI \& DAVID BARRINGER, LEGAL VISIONARIES: HOW TO MAKE THEIR INNOVATIONS WORK FOR YOU (2013).

69 Id.

70 Smith, supra note 30. 
include complex hospital mergers, investments in new medical technology, appealing Medicare audits, or handling reimbursement disputes..$^{71}$ Other areas in which outside firms are well positioned to help health care clients include "capital markets, private equity, white collar crime and securities enforcement."72 Generally speaking, in-house counsel is more likely to outsource, under their supervision and management, representations that are ad hoc, highprofile, unique and specialized. ${ }^{73}$

The increased need for specialization by health care clients is forcing general health care lawyers to reevaluate their role in the corporate law firm. Some outside health lawyers are finding narrower niches in private law practice to thrive and survive. For example, one health lawyer who started out representing small clinics and nursing homes developed a specialty in Medicare appeals that earned him a national client base. ${ }^{74}$ Other health care lawyers in private practice may find niche areas in the types of clients they serve, such as alternative health care providers or behavior health specialists, rather than the large health care clients that once were the mainstay of large law firms. ${ }^{75}$

Other general health care lawyers in private practice may find themselves playing the role of client visionary and manager. One in-house general counsel stated recently, "I need lawyers to make important breakthroughs, both large and small."76 For outside law firms to make those important advances and add value to corporate health care clients, the firm needs collaborative teams of lawyers from different disciplines to strategize about the client's needs and role for the future. The outside "general" health lawyer may serve as the "glue" for those multidisciplinary teams

71 Id.

72 Larry Ribstein, The Death of Big Law, 2010 WIS. L. REV. 749, 775 (2010).

73 Wald, In-House Myths, supra note 15, at 415; see also Lipson et al., supra note 18 , at 243 ("Corporations typically outsource matters that are large, complex, or specialized.").

${ }_{74}$ Smith, supra note 30.

75 Wald, In-House Myths, supra note 15, at 413.

76 GALBENSKI, supra note 68, at 101. 
and lead those teams, despite having to increasingly rely on lawyers with specialized expertise to fill the void that may exist in the in-house legal department.

Skilled outside health lawyers will know the direction in which the winds of health industry change are blowing, particularly with regard to forthcoming regulatory changes, and can advise clients accordingly. Indeed, in most instances, the regulatory winds blow in the direction of closing monetary loopholes and trying to strengthen the underlying "triple aim" of health care: better health, better care and lower costs. Effective corporate health lawyers feed the dueling desires of corporate health care clients with ideas and innovations that strive to provide the best, medically necessary care while generating revenue.

For example, as noted earlier, the ACA is encouraging merger and consolidation with the growing interest in ACOs. Yet, not all health care practitioners and clients are embracing that trend, while others may feel left out because, for example, the Medicare Shared Savings Program only allows certain providers to form a Medicare ACO (see e.g., 42 CFR 425.102(a)). Outside health lawyers can help frame a proud existence for those clients on the fringe of the consolidation trend through legal entities, such as the Independent Practice Associations (IPAs), 77 that help providers maintain independence while boosting negotiating power in the marketplace. Indeed, as more managed, integrated systems continue to move from the West to the East Coast across the United States, outside lawyers with specialized knowledge in creating these larger, integrated structures or finding legal alternatives to stay independent will be in high demand. ${ }^{78}$

77 IPAs consist of "a network of physicians who agree to participate in an association to contract with health maintenance organizations (HMOs) and other managed care plans. Although physicians maintain ownership of their practices and administer their own offices, the IPA serves as a corporate structure for negotiating and administering HMO contracts for its physician members." K. Grumbach et al., Independent Practice Association Physician Groups in California, 17 HEALTH AFFAIRS 227, 227 (1998).

78 Id. at 227-28 (noting IPAs and other physician integrated models are prominent organizational structures in the western states whereas 
Since the outside health care lawyer is seen as independent from the client, as well as knowledgeable, the lawyer can help advocate and legitimize these legal arrangements and tout his or her effectiveness to not only the client, but the community at large. ${ }^{79}$ In other words, corporate health lawyers who are intimately familiar with the health care industry are in a position to shape their practice to influence clients and create discursive diffusion around achieving alternative and beneficial ways of providing patient care. ${ }^{80}$ Moreover, the independence of the outside lawyer frees him or her from many of the conflicts of interest that arise in the in-house context and thereby opens up opportunities to work in the community to improve social determinants of health. This community work may be in the form of pro bono representation, such as with medical-legal partnerships (discussed below), board memberships and public representation on committees. ${ }^{81}$

\section{B. Expanding Medical-Legal Partnerships ${ }^{82}$}

One of the sites for practice for improved and patientcentered health care is medical-legal collaborations. The medical-legal partnership (MLP) developed at Boston

in other regions of America, HMOs contract directly with individual physicians); see also Boozang, supra note 13.

79 See, e.g., Gordon, supra note 55 ("As intermediaries between corporate clients and powerful outsiders - investors, creditors, and stockholders as well as local, national and foreign governments - and as cosmopolitans attuned to popular and foreign public opinion, corporate lawyers were frequently in a position to tell their clients that some proposed action would have adverse [or positive] long-run effects.").

80 Zabawa et al., supra note 40.

81 In-house counsel may also provide community work within the limits of conflicts of interest.

82 Some of the materials in this paper on medical-legal partnerships, along with the discussion of lawyers as colleagues with doctors and other professionals, are from an article by Paula Galowitz, one of the co- $^{-}$ authors; that article is Paula Galowitz, The Opportunities and Challenges of an Interdisciplinary Clinic, 18 INT'L J. CliniCAL LEGAL EDUC. 163 (2012). 
Medical Center in 1993 was one of the first. ${ }^{83}$ There are a variety of models for medical-legal collaborations. Many, but not all, are listed on the website of the National Center for Medical-Legal Partnership (NCMLP). ${ }^{4}$ According to that website, there are 262 medical-legal partnerships in 36 states, with 135 hospitals, 127 health centers, 35 health schools, 127 legal aid agencies, 46 law schools, and 70 pro bono partners. ${ }^{85}$

MLPs can occur in diverse contexts or be targeted to specific populations, such as children, the elderly, victims of domestic violence, or patients with cancer. Typically, MLPs have a multidisciplinary, ${ }^{86}$ holistic and preventive approach to help address the multidimensional problems faced by patients/clients that impact health. Legal assistance is integrated into the health care delivery model. The lawyers provide legal advocacy in a medical setting for clients referred by medical professionals. It is a "multidisciplinary model [that] can respond to the myriad needs of those who are poor or marginalized by their social, medical or psychological circumstances." 87 These partnerships can

${ }^{83}$ Ellen Cohen et al., Medical-Legal Partnership: Collaborating with Lawyers to Identify and Address Health Disparities, 25 J. GEN. INTERNAL MED. 136, 138 (2010).

84 The National Center, NAT'L Ctr. For Med.-Legal P'ShIP, http://medical-legalpartnership.org/national-center/ (last visited Dec. 28, 2014) [hereinafter NCMLP] (The NCMLP was formed in 2006 to guide the expansion of the medical-legal partnership model; in 2013 the National Center became a project of what is now called the Milken Institute School of Public Health, George Washington University).

85 Partnerships Across the U.S., NAT'L CTR. For MED.-Legal P'SHIP, http://www.medical-legalpartnership.org/partnerships/ (last visited Dec. $28,2014)$.

86 The terms "interdisciplinary" and "multidisciplinary" are sometimes used interchangeably but they have different meanings. "Multidisciplinary" implies that each discipline approaches issues from its own perspective, staying in its own "silo," more akin to separate but equal, while "interdisciplinary" implies a more integrated teaming among disciplines. See Rebecca L. Jessup, Interdisciplinary Versus Multidisciplinary Care Teams: Do We Understand the Difference, 31 Austl. HeAlth REV. 330, 331 (2007).

87 Stacy L. Brustin, Legal Services Provision Through Multidisciplinary Practice-Encouraging Holistic Advocacy While Protecting Ethical Interests, 73 U. CoLO. L. REV. 787, 792 (2002). 
improve the health and well-being of low-income communities and other vulnerable populations by meeting legal needs of the individuals and helping to alleviate legal barriers to health.

Many patients and clients have issues in which it can be difficult to separate the legal aspect from that which is typically associated with other disciplines. Patients can present with a multitude of psychosocial issues, including family disruption (due to illness, incarceration, violent injury, child abuse and/or neglect), poor housing, unemployment and poverty, domestic violence, lack of access to health care, and immigration problems. Some legal-related issues can affect the health of individuals. Furthermore, many of the problems that affect the health of children and families have legal remedies. Many legalrelated issues can affect the health of the patients, such as asthma triggered by mold from leaky ceilings or rodent infestation; lead poisoning from paint not removed; burns caused by families heating apartments with stoves; and children's failure to thrive due to lack of sufficient food.

Many of these partnerships have a three-fold approach: direct legal representation, changes to clinical or institutional policy, and systemic policy changes. The mission of the NCMLP is:

to build a healthcare system that deploys the expertise of the country's existing public and pro bono civil legal aid community to identify, treat and prevent health-harming legal needs as part of basic, quality healthcare at every healthcare institution serving low-income people . . . [T] his transformation is critical to helping the most vulnerable Americans get and stay healthy. 88

882014 Medical-Legal Partnership Summit, http://www.cmesam. com/PubCMEDetails.aspx?id=7301 (last visited January 5, 2015). 
The passage of the ACA is enabling MLPs to enlarge the need for and potentials of medical-legal collaborations. ${ }^{89}$ The ACA has placed population health and prevention as a crucial element in health care, creating incentives for hospitals and health care providers to look outside the walls of the health care institutions to see what can keep patients healthy. Lawyers can be part of the team and must be included as the health world moves to interprofessional practice. Legal needs of patients that impact health must be included in the broader context of the health world. ${ }^{90}$ Moreover, medical-legal collaborations can serve larger numbers of vulnerable populations in a variety of ways, including through training of health care professionals and innovations in clinical care.

One of the critical designs of the ACA is the support for community-based care; the Act "augment[s] the health care safety net by supporting community health centers, community-based care, and community-health-needs assessments." 91 Changes to the Internal Revenue Service (IRS) reporting requirements for non-profit hospitals are connected to this element of the Act; the hospital must report its community benefits in order to maintain the hospital's non-profit status.92 In addition, non-profit hospitals have to complete and present a community health

89 See, e.g., Joel Teitelbaum, Obligation and Opportunity: MedicalLegal Partnership in the Age of Health Reform, 35 J. LEGAL MED. 7 (2014); James Teufel et al., Rural Health Systems and Legal Care: Opportunities for Initiating and Maintaining Legal Care After the Patient Protection and Affordable Care Act, 35 J. LEGAL MED. 81 (2014); Diane M. Goffinet et al., Medical-Legal Partnerships in the Age of the Affordable Care Act, 47 Clearinghouse Rev. 265 (2013).

90 "Health-harming legal need" has been defined as a "social problem that adversely affects a person's health or access to health care, and that is better remedied through legal-medical collaboration rather than health care services alone." Joel Teitelbaum, The ACA and Community Impacts: The Role of Medical-Legal Partnership, NAT'L CTR. FOR MED.LEGAL P'SHIP (April 25, 2013), available at https://uwphi.pophealth.wisc.edu/programs/healthpolicy/ebhpp/events/20130425/teitelbaum.pdf, archived at https://perma.cc/U798-DA8U.

91 Goffinet, supra note 89, at 267.

92 Id. 
needs assessment in order to be in compliance with nonprofit tax-exempt 501(c)(3) requirements. ${ }^{93}$ These community benefits include:

[p]rograms and services designed to meet community health needs, increase access to health care, and respond to the needs of vulnerable populations. Community benefits activities fulfill a health system's commitment to provide care to those who are unable to pay and those who are members of traditionally vulnerable and underserved groups. Community benefits are mission driven, often supplying services or programs with a low or negative profit margin-programs that would likely be discontinued if the decision were solely financially driven. Community benefits include uncompensated (charity) care, free and reduced-cost services . . . research, medical education, and other in-kind services. ${ }^{94}$

These required community needs assessments should encourage medical-legal collaborations since they increase access to health care and respond to the needs of vulnerable populations. Moreover, the hospitals can see the MLPs as a vehicle for providing the community benefits in a coordinated fashion linked to health outcomes. Hospitals can satisfy the community benefits requirement though financial and logistical support for MLPs.

The ACA also aims to reduce health disparities, and medical-legal collaborations are one of the ways to do that. "Medical care is only responsible for approximately 10 to 15 percent of what determines health ... physicians cannot do it all by themselves. They need to work collaboratively with other professional to address the root causes of disease." ${ }^{95}$

93 Id.

94 Id. at 268.

95 Interview with David R. Williams, Professor of Public Health, Harvard School of Public Health (July 10, 2013) ("A national commitment is needed to eradicate health disparities"). 
It is well documented that social determinants like housing and income can impact health. ${ }^{96}$ In addition to the lawyers in the collaborations helping to resolve the legal problems that impact health, the lawyers can help train health care professionals to recognize the legal issues both for the referrals and, in some situations, the health care professionals can help resolve the problems. ${ }^{97}$ For example, lawyers in a medical-legal collaboration could train the doctor or other health care professional with advocacy tools to challenge the termination of a patient's utility when the patient's health is at risk.98 Lawyers and health care professionals can also create a standardized order for mold removal in the living conditions of their patients that could be a routine part of the doctor's protocol, which is completed and submitted by the doctor to the appropriate actors (such as the local agency responsible for enforcement of housing conditions or the owner of the property). ${ }^{99}$

Two other features of the ACA highlight the increased need for medical-legal collaborations. One is the emphasis on financing care, which leads to "innovative and integrated methods to change health systems to improve patient and population health" 100 such as medical-legal collaborations, which integrate medical and legal care. The other is the focus on promoting population health. Examples include penalizing hospitals for readmissions within thirty days of discharge. ${ }^{101}$ MLPs have the

96 Ellen M. Lawton, Integrating Healthcare and Legal Services to Optimise Health and Justice for Vulnerable Populations: The Global Opportunity, 2 L. OF THE FUTURE AND THE FUTURE OF L., 73 (2012), a vailable http://www.fichl.org/fileadmin/fichl/documents/LOTFS/LOTFS_1_Web.p df

97 Galowitz, supra note 82.

98 Goffinet, supra note 89, at 270.

99 Telephone Interview with Ellen Lawton, Co-Principal Investigator, Nat'l Ctr. for Med.-Legal P'ship (Dec. 4, 2013).

100 Goffinet, supra note 89, at 271.

101 Patient Protection and Affordable Care Act, Pub. Law. No. 111148, § 3025, 124 Stat. 119, 408 (2010). 
Potential to be part of a strategic plan to develop and implement processes to reduce avoidable emergency department visits and reduce avoidable readmissions. . . . Navigating the legal as well as the health care system can help individuals and their families avoid returning unnecessarily to a medical provider for a recurring condition. ${ }^{102}$

The MLPs not only create a framework for providing better health care and outcomes, they can also serve as a linchpin for legal services. A recently created fellowship program designed to build health care expertise in the legal aid community provides training for twenty-four senior level staff in legal aid agencies to deepen their understanding of health care organizations, financing and priorities. ${ }^{103}$ Linking traditional poverty law services to improving health care provides the lawyer with medical colleagues, potential funding and effective client services. It places legal needs in the broad context of the health world.

"Health justice"104 can also serve as a marketing device for more funding from the health care sector and the corporate sector. MLPs are emerging as a dynamic method to deliver legal services to individuals. It links assistance for people with legal needs to health care, a growing sector with public and private funding and delivery. The MLPs utilize many of the sectors that deliver legal services for people: legal aid, law school clinics, community centers, and

102 Goffinet, supra note 89, at 271.

103 The NCMLP and the National Legal Aid and Defender Association (NLADA) recently announced new fellowships to build health care expertise in civil legal services. See New Fellowship Launched to Build Healthcare Expertise Among Civil Legal Aid NLADA (March http://www.nlada100years.org/node/16148, http://perma.cc/RT2L-VKAQ [hereinafter NLADA].

104 The medical-legal partnership clinic at Loyola University Chicago School of Law is called the "Health Justice Project." Health Justice Project, Loyola UNIVERSity CHICAGo SCHOOL OF LAW BEAZLEY INSTITUTE FOR HEALTH LAW AND POLICY, http://luc.edu/law/centers/healthlaw/hjp/index.html, archived at http://perma.cc/FHJ7-C5YZ (last visited Dec. 28, 2014). 
pro bono services. While some of the lawyers are practicing pro bono, many of the programs are staffed by legal aid lawyers. The increase and growth in the number of MLPs can result in the creation of new jobs. ${ }^{105}$

In addition to assistance for patients, MLPs can be important parts of the health institutions that serve the poor. The federally qualified health centers are important components of service for the poor and disadvantaged and the MLPs often provide services for their patients. Lawyers can play an integral role as these community based health centers figure out their place in the evolving health care sector. ${ }^{106}$

\section{LEARNING From THE WORKPLACES: RECONSTRUCTING LAWYERS' PROFESSIONALISM IDENTITY ${ }^{107}$}

The changing context requires lawyers to adapt at their workplaces. The preceding sections describe how workplaces are adapting and experimenting. Each of the sites has distinctive challenges based on the particular way they are interacting with health care patients, providers and institutions. Yet, in all three, lawyers are dealing at the workplace with how to reconstruct professional identity. ${ }^{108}$ These adaptions can be described as creating "bottom-up professionalism," looking at lawyers' work from the bottom up, from the perspective of lawyers in a

105 See Daniel Atkins et al., Medical-Legal Partnership and Healthy Start: Integrating Civil Legal Aid Services into Public Health Advocacy, 35 J. LEGAL MED. 195, 208 (2014) ("In addition to improving individual and population health and well-being, the MLP model may be a more sustainable method to fund poverty law services due to its value to healthcare partners.").

106 Lawton, supra note 99.

107 We are using "professionalism" to mean "the set of norms, traditions and practices that lawyers have constructed to establish and maintain their identities as professionals and their jurisdiction over legal work." LAWYERS' IDEALS/LAWYERS' PRACTICES; TRANSFORMATIONS In The American Legal Profession 5 (Robert L. Nelson et al. eds., 1992).

108 See id. (discussing constructing professionalism at workplace). 
specialized practice, not from the top-down rules. ${ }^{109}$ One way to look at these adaptations is to place them in three categories: expertise, roles and communities of practice. ${ }^{110}$

\section{A. Expertise}

The workplace stories demonstrate many changes in the relationship the lawyer has with his or her clients and with health care professionals. The ACA encourages health care to move towards collaboration among providers and pay attention to patient engagement. These shifts flatten the traditional hierarchy of relationships. It also encourages more input from various participants that can result in "collaborative intelligence" as the alternative to "professional expertise." Yet when we look at the workplace sites there are examples of lawyer expertise that are valuable in these collaborations and engagement. In this paper, we highlight three areas in which the expertise of the health lawyer is contributing to this recalibrating of relationships in health care. One is that the expertise of the lawyer (and other professionals) is and should be increasingly negotiated with the patient/client, ${ }^{111}$ which leads to improved health care. ${ }^{112}$ Second, the in-house lawyer's expertise in navigating disputes is changing the lawyer's relationship with medical and other types of professionals. Third, because of the uncertain regulatory landscape, there is an increased valuation of the lawyer's

109 LaWyers In Practice: Ethical Decision MaKing In CONTEXT 11 (Leslie C. Levin and Lynn Mather eds., 2012).

110 These categories are adapted from the extensive literature that studies the construction of professionalism at the workplace. See Philip Lewis, Aspects Of Professionalism, in THE PARAdOX OF PROFESSIONALISM 132-52 (Scott Cummings ed., 2011). See also LynN MATHER et al., DIVORCE LAWYERs AT WORK: VARIETIES OF Professionalism In PraCtice (2001).

111 This is not a new phenomenon but one that is ever increasing and changing.

112 For a discussion of the importance of doctors and patients participating in mutual sharing of decisions and the barriers to it, see, e.g., A.M. Capron, The Legacy of Jay Katz: The Abiding Relevance of the 'Obligation for Conversation' in the Physician-Patient Relationship, 2 J. HEALTH \& LifE SCIENCES L. 1 (2009). 
expertise by the health care industry in making strategic business decisions.

\section{Legal Expertise for Improved Patient-Centered Care}

A particularly relevant example of how negotiated changes in the lawyer's expertise affects improved health care is with the issue of informed consent. As noted in a recent article, "significant barriers to effective decisionmaking continue to exist in part due to the medical and legal visions of informed consent as a legal requirement mandating a ritualistic but limited communication between physicians and patients." 113 Changes in approaches to informed consent could result in a "more effective patientcentered communication process that invokes shared decision-making among patients, health care providers, family members, and community health workers, all of whom need to be involved in consent for care."114 To have improved health literacy, which impacts health care dramatically, there need to be changes in the legal rules so there can be shared decision-making. For example, the State of Washington has enacted legislation that protects doctors who engage in shared decision-making by creating a legal presumption in favor of the doctor where the patient signed an acknowledgment of shared decision-making; that is prima facie evidence of informed consent that can only be rebutted by clear and convincing evidence. ${ }^{115}$ Changes such as the Washington law can help minimize doctor concerns about tort liability for shared decision-making. ${ }^{116}$ Lawyers working within MLPs can advocate for laws to facilitate improved patient-centered care.

113 Frank McClellan et al., It Takes a Village: Reforming Law to Promote Health Literacy and Reduce Orthopedic Health Disparities, 8 J. HEALTH \& BiOMEDICAL L. 333, 336 (2013).

114 Id.

115 WASH. REV. CODE $§ 7.70 .060$ (2015)

116 The possibility of doctor liability is sometimes cited as a barrier to shared decision-making. See McClellan, supra note 113, at 373. 


\section{Legal Expertise to Resolve Complaints}

There are similarities at the three sites in the role of the lawyers in the interaction between the lawyer and the medical world. These health law practitioners can bridge gaps in knowledge that health care professionals may have about legal professionals and tear down negative stereotypes. One view health professionals may have of lawyers derives from malpractice actions. Some doctors associate lawyers as "ambulance chasers" who sue them in malpractice actions. Health lawyers can show doctors and other professionals that the practice of law does not exclusively entail litigation; rather, lawyers provide guidance, create strategies and resolve problems outside the court room.

Another assumption comes from different views of autonomy of the patient and the client. For most lawyers, the client dictates the result of the relationship. However, for some doctors it is the doctor who advocates as the expert for what the doctor thinks is best for the patient.117 The presence of a lawyer working inside a health care organization can demonstrate alternatives to patient relations. An in-house lawyer's involvement in mediating disputes between providers and patients is an example of an evolving role of the lawyer as an intermediary between the medical world and the lawyer's understanding of the utility of disputes. For example, lawyers may use malpractice claims as data for improving care. Lawyers can help fashion benchmarks using malpractice data and collaborate with other professionals, such as clinicians and business operations, to help improve an organization's delivery of health care and thereby reduce patient complaints. As providers move into integrated systems that contain a variety of providers and interests, lawyers can help reconcile differences among those providers to help the integrated system achieve its goals.

117 Zabawa et al., supra note 40. 


\section{Legal Expertise to Strengthen Business Decisions}

The move toward having the lawyer as part of the business team rather than the autonomous outsider has advantages, especially in the perpetually shifting regulatory landscape since the enactment of the ACA. The in-house lawyers have a different set of ethical issues and obligations. These ethical obligations continue to exist despite lawyers working with the business as employees and as part of a multi-disciplinary team. In-house lawyers must preserve their independence and ethical duties while working for the business to develop strategies that are good for the community and bottom line. Lawyers who fail to find this balance and gravitate more toward the business goals without sufficient grounding in their role as the company lawyer may be liable for the conduct of the health institution and put themselves at professional risk.

Nevertheless, it is possible to find the right balance in the business strategy context. For example, in working with a multi-disciplinary team that wishes to take advantage of new federal subsidy programs created through the ACA, referenced above, the in-house lawyer can learn about the business reasons for the goal and evaluate those reasons against the backdrop of government regulations. The lawyer is able to use his or her deep knowledge of legal precedent and dispute resolution to find and document answers on which the company can comfortably rely.

The corporate law firms who serve as independent interpreters of the law must figure out how to serve as an intermediary between the government regulations and the health care stakeholders. The outside lawyers can play a pivotal role in providing an added layer of reassurance to strategic business decisions that such decisions fall within the legal parameters set by the federal and state governments. 


\section{B. Roles: The Lawyer as Colleague with Physicians and Other Professionals}

Professionals are increasingly aware that working together with other professions can better serve clients and improve outcomes. ${ }^{118}$ Leveraging limited resources can result in improved service for patients/clients, where the professions working together can more effectively address problems than could be done by the professions working separately. 119 In addition, there needs to be a "more conscious coordination and integration of delivery of services" to low-income communities. ${ }^{120}$ According to the NCMLP, preliminary local data indicates the multifaceted impact of these collaborations including improvements in health and well-being; medical homes and institutions; clinical workforce skills; legal services and institutions; and policies, laws and regulations. ${ }^{121}$ There are benefits for patients and families, benefits for health care staff, and benefits for the community. ${ }^{122}$

Medical-legal collaborations are one of the ways to reduce health disparities. "Medical care is only responsible

118 Multidisciplinary programs "offer a potentially significant advance in the way legal services are provided to low-income and other marginalized programs.” Brustin, supra note 87, at 794.

119 For a discussion of the effective leveraging of limited resources in medical-legal partnerships, see Randye Retkin et al., Medical-Legal Partnerships: A Key Strategy for Mitigating the Negative Impacts of the Recession, 22 HEALTH LAW 29 (2009).

120 Dina Schlossberg, An Examination of Transactional Law Clinics and Interdisciplinary Education, 11 WASH. U. J.L. \& POL'Y 195, 210 (2003).

121 NCMLP, supra note 84.

122 See Evidence Base for Medical-Legal Partnership, NCMLP, http://medical-legalpartnership.org/wpcontent/uploads/2014/03/Summary-of-Evidence-Base-for-Medical-LegalPartnership.pdf, archived at http://perma.cc/VR3P-DWXT (last visited Dec. 28, 2014) (according to the NCMLP, the benefits for patients and families include compliance with health care, treatment of chronic diseases, treatment of asthma and reduction of stress; the benefits for health care staff are improved health care staff knowledge and screening efficacy, and increased health care staff satisfaction; the benefits for the community are the financial savings, public benefits recovery for patients and improved population health). 
for approximately 10 to 15 percent of what determines health. . . . physicians cannot do it all by themselves. They need to work collaboratively with other professionals to address the root causes of disease."123

While there are many benefits to the increased collaboration between lawyers and physicians, it is important to acknowledge that there are differences in the professions, which pose challenges for these collaborations to occur and thrive. These differences, which are deepseated and emanate from many sources, include education, training and socialization. There are also differences in the language, customs and norms of the two professions. In addition, the legal and medical professions have their own culture, values and definitions of roles that can impact effective interactions. The variations in role are very broad, including views of role in society and roles in relation to clients/patients.

Significant sources of the barriers to collaboration between lawyers and health care professionals are the ethical obligations and professional values of the two professions. Additionally, the differences in ethical obligations such as confidentiality, conflicts of interest, responsibilities to the client/patient, and the independence of the professional must be addressed. As to the different professional ethics, there are different definitions in a variety of areas, including who is the "client," confidentiality, conflicts and capacity of the person to make decisions. ${ }^{124}$

123 David R. Williams, A National Commitment is Needed to Eradicate Health Disparities, ROBERT WOOD JOHNSON FOUNDATION (July 10, 2013), http://www.rwjf.org/en/about-rwjf/newsroom/newsroomcontent/2013/07/a-national-commitment-is-needed-to-eradicate-healthdisparities.html, archived at http://perma.cc/PA3A-9K5U.

124 Some literature has discussed some of the ethical issues and professional conflicts in medical-legal collaborations. See, e.g., Marcia M. Boumil et al., Multidisciplinary Representation of Patients: The Potential for Ethical Issues and Professional Duty Conflicts in the Medical-Legal Partnership Model, 13 J. Health CaRe L. \& Pol’y 107, 123 (2010); J. Michael Norwood \& Alan Paterson, Problem-Solving in a Multi-Disciplinary Environment? Must Ethics Get in the Way of Holistic Services?, 9 CliniCAL L. REV. 337, 357 (2002); Jacqueline St. Joan, Building Bridges, Building Walls: Collaboration Between 
The changing roles of the professions highlight the need for multi-disciplinary advocacy. While there has been considerable opposition in the organized bar to lawyers working with other professions, that opposition has primarily been in the private sector between lawyers and financial persons. ${ }^{125}$ Commentators have discussed the different reasons for multidisciplinary practice in public interest practice, ${ }^{126}$ yet there continues to be resistance to multidisciplinary practice. The changes in health law practice provide another reason to revisit the ethical bans on multidisciplinary practice.

A key component of overcoming challenges is for the members of the interaction to have transparent and agreedupon goals and values for the collaboration. There should be a structure that formalizes the relationship and anticipates the possible problem areas. ${ }^{127}$ Moreover, the collaboration needs to use and rely on the knowledge of all of the disciplines and be part of a comprehensive approach to meet the needs of the patients/clients. An additional component is a commitment to the importance of developing creative approaches to assist patients/clients.

One important way to improve the methods and outcomes of professional collaboration is to spend sufficient time with the other professionals in planning the professional interaction at the worksite. Many of the challenges can be anticipated and addressed beforehand. While dealing with them can be challenging, they are not

Lawyers and Social Workers in a Domestic Violence Clinic and Issues of Client Confidentiality, 7 CLINICAL L. REV. 403 (2001).

125 Commission On Multidisciplinary Practice, AMERICAN BAR AssociaTION,

http://www.americanbar.org/groups/professional_responsibility/commiss ion_multidisciplinary_practice.html, archived at http://perma.cc/3P839YXV (last visited Dec. 28, 2014).

126 See, e.g., Brustin supra note 87.

127 See Norwood \& Paterson, supra note 124 (as stated by the authors in their description of a multidisciplinary practice in which the University of New Mexico Child Advocacy Clinic is the legal services provider, the professionals need to work out "an organizational structure that formalizes their relationship and addresses the complexities of responding to ongoing client needs in a manner that both maximizes efficiency of effort and minimizes ethical pitfalls."). 
barriers, particularly if the anticipated issues are discussed and addressed amongst the various professionals in the collaboration. ${ }^{128}$ Guidelines and protocols for the anticipated ethical issues (such as what information received from the client can be shared with the other professionals) should be drafted together as part of the development of the collaboration.

Doctors and lawyers can learn from each other and appreciate the differing professional cultures and skills as well as the problem-solving approaches of the other profession. ${ }^{129}$ Part of that includes learning to understand each other's language, ethics, professional values, and approaches to our clients/patients. As a result of the interaction, the professionals can learn about the roles, boundaries and limits of each member of the collaboration, as well as gain familiarity with the knowledge base of the other profession. This broadening of perspective can lead to what is described as a higher level of cognitive processing, what some psychologists define as "wisdom."130

This interaction between the professions can allow for a "window" in which each profession can reconsider their own professional roles and help each of the professions form (and change) their own views of their profession and their roles in it. This "window" may lead to changes in the professional norms of each. For example, lawyers may need to have more flexible work schedules to allow for clients that need

128 See Paula Galowitz et al., Ethical Issues in Medical-Legal Partnership in Poverty, Health and LaW: REAdings AND Cases For MEDICAL-LEGAL PARTNERSHIP 157-80 (Elizabeth Tobin et al., eds. 2011).

129 See Boumil et al., supra note 124, at 123. "With these diverse cultures and problem-solving approaches, collaboration between these professionals [lawyer, doctor, social worker and other professionals in a medical-legal collaboration] results in a formidable team that provides holistic interventions.").

130 See Anita Weinberg \& Carol Harding, Interdisciplinary Teaching and Collaboration in Higher Education: A Concept Whose Time Has Come, 14 WASH. U. J.L. \& POL'Y 15, 23 (2004) ("It is this higher level of cognitive processing - what some psychologists define as 'wisdom'-that we see as the ultimate outcome of interdisciplinary higher education."). 
immediate legal assistance outside of the typical work hours. 131

Another value of the collaboration amongst professions is that the interaction can also increase satisfaction; the collaboration can be a more satisfying and fulfilling professional and personal experience for all. It can also result in increased comfort in being able to learn from and rely on the other professionals. Patients/clients also benefit from interactions by offering more creative and better service for the clients. ${ }^{132}$ It can result in the professionals being engaged in more creative problem-solving to promote access to justice and health services. The collaboration empowers the professionals to serve their clients/patients in new and better ways.

\section{Communities of Practice}

For lawyers changing their ways of practice, groups of like-minded people can support lawyers' views of how to behave. These communities can support the lawyers when they create or join workplaces that deviate from the traditional law firm model. Typically, lawyers don't collaborate with other professions, while some of these communities of practice do. The new ways of practice also raise issues of ethical compliance. The workplaces are locations for figuring out how to effectively serve clients in the context of the rules of professional conduct. This can be seen as dealing "bottom-up" with ethical dilemmas. ${ }^{133}$

131 See Lynn Hallarman \& Denise Snow, The Medical-Legal Partnership: An Alliance Between Doctors and Lawyers in the Care of Patient-Clients with Advanced Life-Limiting Illness, 17 N.Y. ST. BAR Ass'N HEALTH L. J. 1 (2012) (noting that lawyers working in a medicallegal collaboration may need to be available for seriously ill patients at atypical hours).

132 See Brustin, supra note 87, at 794 ("An interdisciplinary model also has the potential to encourage lawyers to create innovative programs that not only respond to the perceived needs of client communities but also actively involve clients in bringing about social change.").

133 See Sung Hui Kim, The Ethics of In-House Practice, (UCLA School of Law, Law-Econ Research Paper No. 11-12, 2011) available at http://papers.ssrn.com/sol3/papers.cfm?abstract_id=1919276, archived 
Communities can support lawyers in the creation of an alternative identity and "shape the norms of practice."134

MLPs and in-house counsel have networks of colleagues and local and national associations that provide this support. The MLPs have a national partnership that hosts conferences, provides networking for local programs, initiates fundraising, supports legislation to improve their funding, and encourages effectiveness research. ${ }^{135}$ The NCMLP is instrumental for the dissemination of the model of closely linked legal/medical provision of services to improve health care outcomes. In addition to the NCMLP, there are other support communities in medical-legal collaborations. For example, in New York there is the New York State Coalition of Medical-Legal Partnership, which has held conferences, coordinated funding and advocated for the successful passage of the Health-Related Legal Services Program in the New York State Legislature. ${ }^{136}$

In-house counsels have associations that have been leading the effort for a while to raise the status and position of in-house lawyers. One example is the Association of Corporate Counsel; this group is active in advocating on public issues such as regulating the profession and legal education training. ${ }^{137}$ The Association of Corporate Counsel hosts educational programs on matters of special interest to in-house counsel, such as lawyer-client privilege and ethical issues facing in-house lawyers. ${ }^{138}$

Both in-house and outside health lawyers benefit from other communities of practice, such as the American Health

at http://perma.cc/E4XR-2R9D; Scott Cummings, The Accountability Problem in Public Interest Practice: Old Paradigms and New Directions, in LAWYers IN PRACTICE: ETHICAL DECISION MAKING IN CONTEXT 340-64 (Lynn Mather \& Leslie Levin eds., 2012)

134 Mather et al., supra note 110.

135 See NCMLP, supra note 84.

136 N.Y. Public HEALTh LAW § 22 (McKinney 2012)

137 Wilkins, supra note 14.

138 See, e.g., Beverly Jones \& Peter Tomlinson, Presentation for ACC America, Greater New York Chapter, Privilege and Ethical Issues for In-House Counsel 2013 (Apr. 17, 2013), available at http://www.acc.com/chapters/gny/upload/PBWT-Ethics_PrivilegeCLE_April-17-2013-2.pdf. 
Lawyers Association, which hold in-person meetings on a variety of health law topics including Medicare and Medicaid reimbursement, tax, health information privacy and security, and a special program for in-house counsel. ${ }^{139}$ Collaborative organizations that were born out of the Health Insurance Portability and Accountability Act (HIPAA) privacy and security regulations helps both inhouse and outside lawyers navigate these sticky health law issues. For example, the HIPAA Collaborative of Wisconsin held a roundtable for HIPAA privacy professionals to discuss best practices in handling a variety of health information privacy matters. ${ }^{140}$ These communities of practice mitigate feelings of isolation or frustration that accompany a changing or challenging practice landscape.

\section{TRAINING FOR PRACTICE}

The health workplace sites demonstrate the need for lawyers today to have competence in new areas in addition to the traditional learning of legal rules and regulations. These lawyers need to master the ability to work in multiprofessional collaborations, have a broad knowledge of substantive areas, understand the complexity of legal roles, and deal with ethical concerns. Health lawyers are developing these skills and going beyond the traditional forms of knowledge. While practicing lawyers are coping with these new demands, the law schools lag behind. Change has been very rapid and law schools have generally not responded to all the transformations in law and practice.

139 See, e.g., Past Programs, AHLA, http://www.healthlawyers.org/ Events/Programs/Pages/Past.aspx, archived at http://perma.cc/9FGWJE49; see also Wald, In-House Myths, supra note 15, at 436 (noting that there is a proliferation of bar associations offering a venue for interacting with lawyers who practice in the same fields of law, or hail from the same or similar backgrounds).

140 See, e.g., Dan Weissburg, Presentation at the HIPAA COW 2014 Spring Conference: Pragmatic Privacy Professionals Collaborative Roundtable: Hearing the Heard (Apr. 11, 2014) (brochure available at: http://hipaacow.org/event/2014-spring-conference/, archived at http://perma.cc/E733-5HSR). 
Some law schools have specialized programs in health law. ${ }^{141}$ These programs offer courses on substantive areas of health law, and may offer certificate programs and masters of law in health. ${ }^{142}$ There are joint degree programs with public health and medical schools. ${ }^{143}$ A few law schools provide clinics and externships where students are placed in medical and health care settings. ${ }^{144}$ There are fewer opportunities for collaborative business, health care and law training; law school health law programs for example often do not emphasize business skills. ${ }^{145}$

It is in the law school that the ethical issues arising from these changing ways of practice can be addressed. The required professional responsibility course can discuss the variety of issues that arise in multidisciplinary collaborations, such as MLPs. ${ }^{146}$ Similarly, the complicated ethical issues for in-house counsel and corporate counsel in health law practices, previously discussed in this paper, can and should be incorporated into existing professional responsibility courses. However, the slowness of the law school responses to the transformation leaves the law students lacking information about the health law field and opportunities to develop the new skills it demands. While health law teachers and programs are trying to

\footnotetext{
141 See Formal JD/MPH Degree Programs, supra note 1; Health Law Programs, supra note 1; Health Law Section, supra note 1.

142 Id.

${ }^{143} I d$. Joint degrees can be affordable by using expedited programs and providing placements that provide access to job opportunities.

144 See NCMLP, supra note 84 (the NCMLP website has a listing of law schools with some form of a MLP clinic); see Paula Galowitz, The Opportunities and Challenges of an Interdisciplinary Clinic, 18 INT'L J. Clinical LEGAL EDUC. 163 (2012) (discussing the Medical-Legal Advocacy Clinic at New York University School of Law).

145 See Carl J.Circo, An Educational Partnership model for Establishing, Structuring, and Implementing a Successful Corporate Counsel Externship, 17 CliniCAL L. REV. 99 (2010) (the article on careers in corporate practice studying the relationship between in-house practice and corporate law firms emphasized that law students need to complement their legal skills with business skills such as strategy, budgeting, value marketing, and leadership).

146 Paula Galowitz et al., Ethical Issues in Medical-Legal Partnership, in POVERTy, Health AND LAW: ReAdings AND CASES For MEDiCAL Legal PARTNERShiPs (Elizabeth Tobin Tyler et al. eds., 2011).
} 
accommodate these needs, more must be done by individual teachers and law school programs.

One approach is to look to the movement within universities to develop interprofessional education (IPE) as training for the increasingly collaborative health workplaces. ${ }^{147}$ This is a growing area where "students from two or more professions learn about, from and with each other to enable effective collaboration and improve health outcomes."148 These IPEs can take many forms and directions. In the health care field, the professions engaged in these trainings are primarily medicine, nursing and social work.

On-site practice experience and formal education can be linked by providing opportunities to share knowledge both ways. One example is externships where students are in practice sites and participate in a seminar where health care issues are discussed and analyzed. ${ }^{149}$ In some locations, students from health professions are trained alongside law students. Some of these are clinics linked with the MLP network and provide live client experience to learn about collaboration and ethical issues. On the other side, communities of practice such as MLPs and corporate counsel groups can join with university IPE programs to discuss ethical dilemmas and collaboration barriers. Law schools can take the lead in expanding the range of opportunities, offering more skill-based options, clinics, externships, and information about the changing health care law job market.

As MLP clinics continue to be developed in law schools, they can link with IPEs and bring legal knowledge to the other professions and vice-versa.150 The shared knowledge

147 See Emily Benfer, Educating the Next Generation of Health Leaders: Medical-Legal Partnership and Interprofessional Graduate Education, 35 J. LEGAL MED. 113 (2014).

148 Id.

149 See e.g., Courses by Title, Skills for Health Law Practice, SETON HALL LAW, http://law.shu.edu/Students/academics/coursesbytitle.cfm (last visited Dec. 28, 2014).

150 Benfer, supra note 147; see also Robert Pettignano et al., The Health Law Partnership: A Medical-Legal Partnership Strategically Designed to Provide a Coordinated Approach to Public Health Legal 
and interaction can provide the skills training with supervision. Moreover, it can lead to cross- training for the faculty teaching the programs. A recent initiative is providing ten faculty fellowships to promote public health law education to "build a learning community among those who teach public health law at professional and graduate schools." 151

The academic training can also be linked with the experiences at the workplaces. For example, guidelines and protocols to aid cross-professional practice are being developed and disseminated at the workplace sites. ${ }^{152}$ The MLPs are an example of how communities of practice develop networks to train and learn together. ${ }^{153}$ On-site practice experience and formal education can be linked by providing opportunities to share knowledge both ways. One example is externships where students are in practice sites and participate in a seminar where health care issues are discussed and analyzed.154 In some locations, students from health professions are trained alongside law students. On the other side, communities of practice such as MLPs and corporate counsel groups can join with university IPE programs to discuss ethical dilemmas and collaboration barriers.

In addition to the shared educational opportunities, interprofessional collaborations can lead to the development of proposed protocols and potential legislation. ${ }^{155}$ IPEs can also lead to continued learning post law-school. Programs are now available for mutual learning even after law school

Services, Education, Advocacy, Evaluation, Research, and Scholarship, 35 J. LEGAL MED 57 (2014).

151 Ten Faculty Fellowships Awarded to Promote Public Health Law Education, Georgia State Center for LaW, Health \& Society (Mar. 4, 2014), http://clhs.law.gsu.edu/2014/03/04/ten-faculty-fellowshipsawarded-promote-public-health-law-education/, archived at http://perma.cc/Z5JW-96DK (program funded by the Robert Wood Johnson Foundation).

152 See earlier discussion in Section (III)(B).

15335 Journal of Legal Medicine (2014), available at http://www.tandfonline.com/toc/ulgm20/35/1\#.U1mSSvldWuJ, archived at (a recent edition of the Journal of Legal Medicine devoted an entire edition to eleven articles about MLPs).

154 See e.g., Courses by Title, supra note 149.

155 Benfer, supra note 147. 
graduation. For example, CUNY School of Law many years ago initiated a successful Community Legal Resource Network (CLRN) where solo practitioners, including health law practitioners, meet together and mentor each other in the law school community. ${ }^{156}$ Similarly, opportunities to link health care expertise with business practices can develop through shared programs with business schools and technology departments. ${ }^{157}$

These communities can build on shared knowledge to influence policy and practice protocols to implement new laws. ${ }^{158}$ One example is the HIPAA collaboratives that developed after the passage of the act. These state-based networks of private practice lawyers, community advocates, and corporate privacy compliance officers worked together to create documents and procedures to enable implementation of the complex federal statute. ${ }^{159}$ Ethical concerns were also shared and discussed. An extensive textbook on readings and cases for MLPs includes a chapter on ethical issues in MLPs. ${ }^{160}$ The Association of Corporate Counsel provides extensive training on ethical issues within its organization to allow the development of interpretations of ethics codes that are adapted to their workplaces. ${ }^{161}$ This might be called "bottom-up professionalism."

These three training arenas, when integrated, provide advantages for students in addition to learning. They offer both access to networks and experience at workplaces that prove valuable opportunities for employment after

156 Community Legal Resource Network, CUNY SCHOOL OF LAW, http://www.law.cuny.edu/clrn.html, archived at http://perma.cc/7TXEYF53 (last visited Dec. 28, 2014) (discussing information about the CLRN program).

157 Well-known examples are the joint MD/MBA and JD/MBA degrees. See Association of $M D / M B A$ Programs, $\mathrm{http}: / / \mathrm{mdmbaprograms.com} / 5 . \mathrm{html}$, archived at http://perma.cc/X2TCHA3F (last visited Dec. 28, 2014).

158 The privacy collaboratives developed during the HIPAA period are one example. See Wendy Netter Epstein, Bottoms Up: A Toast to the Success of Health Care Collaboratives... What Can We Learn?, 56 ADMIN. L. REV. 739 (2004).

159 Id.

160 See supra note 149.

161 See Jones \& Tomlinson supra note 138. 
graduation. ${ }^{162}$ Networks provide an accessible location to link with others in the field. Workplace experience allows students to understand the field and locate mentors. Particularly in a time when the job market is more difficult to penetrate, the investment in well-thought out academic programs that provide learning, networks and field experience will be well worth the educational investment. ${ }^{163}$

\section{CONCLUSION}

Growth in health law practice is shaped and encouraged by the current context of health care and legal careers. The intersection is providing opportunities for rewarding work both in the corporate and personal sectors. There are also challenges as the jobs are reshaped.

Health law practice provides a template for the new lawyer. The ongoing restructuring of the sites for practice and the ways to practice demonstrates that rewarding work continues to be possible in law. Perhaps examination of other areas might reveal similar opportunities. The role of law in complex changing fields is no longer primarily to provide only predictability but rather to assist flexibility, orchestration, problem-solving and social justice.

This is also an opportune time to reconsider training. Legal education is engaged in a massive re-envisioning partly due to the perceived imbalance in the supply and demand for lawyers. Law schools across the country "grapple with fewer applicants and fewer jobs for graduates."164 Paying attention to changing ways of practicing health law and looking to interprofessional

162 Lynn Wood \& Justin Osofsky, Crossing The Charles: The Experiences, Networks and Career Paths of Harvard JD/MBA Alumni, (Aug. 2005) available at http://papers.ssrn.com/sol3/ papers.cfm?abstract_id=812425, archived at http://perma.cc/SP7K-G49D.

163 See Karen Sloan, Legal Jobs Picture: 'We're Not Going Back to 2006', NAT'L L. J. (Apr. 10, 2014).

164 Ariel Kaminer, Pace Picks Ex-Taxi Chief as its Law School Dean, N.Y. TIMES, Feb. 27, 2014, at A25, available at http://www.nytimes.com/2014/02/27/nyregion/pace-law-school-picksyassky-ex-taxi-official-as-dean.html?_r=0, archived at http://perma.cc/458T-Z2ST. 
education can provide law schools with insights into how to better train their students. 